OPEN ACCESS

Edited by: Yan Xu,

Nanyang Technological University,

Singapore

Reviewed by:

Yushuai Li,

University of Denver, United States

Amirreza Naderipour,

University of Technology Malaysia,

Malaysia

*Correspondence:

Gareth Taylor

gareth.taylor@brunel.ac.uk

Specialty section:

This article was submitted to

Smart Grids,

a section of the journal

Frontiers in Energy Research

Received: 21 February 2021

Accepted: 14 May 2021

Published: 21 June 2021

Citation:

Radi M, Taylor G, Cantenot Jô, Lambert $E$ and Suljanovic N (2021)

Developing Enhanced TSO-DSO Information and Data Exchange Based on a Novel Use Case Methodology.

Front. Energy Res. 9:670573.

doi: 10.3389/fenrg.2021.670573

\section{Developing Enhanced TSO-DSO Information and Data Exchange Based on a Novel Use Case Methodology}

\author{
Mohammed Radi ${ }^{1}$, Gareth Taylor ${ }^{1 *}$, Jérôme Cantenot ${ }^{2}$, Eric Lambert ${ }^{2}$ and \\ Nermin Suljanovic ${ }^{3}$
}

${ }^{1}$ Department of Electronic and Electrical Engineering, Brunel University London, Uxbridge, United Kingdom, ${ }^{2} E D F R \& D$ Department, Boulevard Gaspard Monge, Paris, France, ${ }^{3}$ Elektroinštitut Milan Vidmar-Electric Power Research Institute, Ljubljana, Slovenia

The growing penetration of renewable energy sources (RES) in the electrical power sector has increased the amount of distributed generation (DG) units connected at the distribution system level. In this context, new balancing challenges have arisen, creating the need for a novel use case methodology to enable an active role at the distribution system level such that transmission system operators (TSOs) can coordinate with distribution system operators (DSOs) with regard to connected resources for balancing purposes. In this study, the exploitation of the DSO-connected resources for balancing purposes in a market environment is proposed and evaluated via a novel business use case (BUC) methodology based on the categorization of IEC 62913-1. More specifically, in order to address different balancing market situations, two scenarios are considered with regard to the BUC. The first one represents the data exchange between the TSO, the DSO, and the balancing service provider (BSP). The second one represents an alternative scenario where data are exchanged directly between the TSO and the DSO, where the DSO also takes on the role of the BSP. The proposed BUC was also developed in order to validate the required data modeling and exchange mechanisms between DSOs and TSOs in order to exploit DSO-connected resources for overall system balancing purposes across different time scales.

Keywords: balancing market, transmission system operators, distribution system operators, use case, renewable energy sources, TSO-DSO coordination, information and data exchange

\section{INTRODUCTION}

The increasing tendency toward integrating renewable energy sources (RESs) into electrical power distribution networks has created new overall system balancing challenges, leading researchers to investigate the requirement for innovative balancing services and market design (Sbordone et al., 2015; van der Veen and Hakvoort. 2016; Vicente-Pastor et al., 2019). Overall system balancing as well as directly related markets and operational procedures are crucial with regard to ensuring security of supply, in terms of congestion management, frequency, and voltage control (Sbordone et al., 2015; van der Veen and Hakvoort, 2016; Vicente-Pastor et al., 2019). Conventionally, balancing services are provided at the transmission system level by balancing service providers (BSPs), which are responsible for providing such services directly to the(TSOs). However, the increasing large-scale integration of RES at the distribution system level has increased the amount of distributed generation (DG) units connected to the distribution network which tend to be both unpredictable and not 
observable to the TSO, especially in the case of rooftop solar installations (van der Veen and Hakvoort. 2016). Therefore, overall balancing issues arise when considering uncertain DG resource availability and estimating their contribution toward meeting the system peak demand while maintaining the overall system reliability. In order to address such challenges, distribution networks are now moving from passive to more active modes of system operation, such that TSOs will be able to benefit from the use of the resources installed within the system boundaries of distribution system operators (DSOs) for overall system balancing purposes. Consequently, it is also essential to enhance information and data exchange between TSOs and DSOs, in order to enable the appropriate level of coordination between TSOs and DSOs in order to ensure effective and efficient use of flexibility-based services across the whole system (Lembo et al., 2009; Silva et al., 2012; Saint-Pierre and Mancarella 2017; Gerard et al., 2018; Vicente-Pastor et al., 2019).

In recent years, significant novel approaches have been reported regarding enhanced coordination between TSOs and DSOs in order to enable the widespread integration of DG in distribution networks (Silva et al., 2012; Hooshyar and Vanfretti. 2017; Gerard et al., 2018; J. Silva et al., 2018; Natale et al., 2019; Vicente-Pastor et al., 2019). Such approaches require scalability and standardization with regard to information and data exchange mechanisms between TSOs and DSOs in order to access flexibility resources as connected to distribution networks. In reference Gerard et al. (2018), five different TSO-DSO coordination methods are presented and their capability of improving the interaction between TSOs and DSOs is evaluated. Based on their results, it is concluded that the selection of the best suited TSO-DSO coordination method is highly dependent on several key factors, such as the current market design, the state of the network, the type of flexibility service, and the type of DG or RES connected. Silva et al. (2012) investigated the importance of defining the quantity and type of information that TSOs and DSOs should exchange in a real Portuguese network. Vicente-Pastor et al. (2019) has developed three different TSO-DSO coordination methods, consisting of separate markets in each case, a coordinated market based on Shapley value allocations, and a coordinated market including retailers. Results obtained on an actual distribution network in Great Britain show that the coordinated option without retailer inclusion was the most effective and efficient. In a study published by Natale et al. (2019), a market is proposed and demonstrated on a realistically sized distribution network where the DSO takes responsibility for balancing the demand and generation as well as guaranteeing a scheduled profile at the TSO-DSO interface. Voltage control is considered by Ruan et al. (2020) in order to address the increasing integration of DG within the boundaries of distribution networks. Furthermore, several distributed approaches have been proposed in order to effectively manage the high penetration of RES (Silva et al., 2012; Pilo et al., 2017; Li et al., 2019; Yushuai et al., 2020). Furthermore, Hooshyar and Vanfretti (2017) presented a use case based on phasor management unit (PMU) monitoring to support the design of a grid automation system capable of allowing synchrophasor applications to exchange information between DSOs and TSOs.
Although significant effort has been reported with regard to managing the information and data exchange between TSOs and DSOs, the continued growth of flexibility resources within the operational boundaries of the DSO has increased the amount of information being exchanged, making it crucial for the enhanced coordination and cooperation between TSOs and DSOs (Givisiezet al., 2020; Rossi et al., 2020). In Rossi et al. (2020), the main challenges in simulating flexibility markets are investigated, in terms of a cost-benefit analysis for three European countries, Italy, Denmark, and Spain, based on 2030 scenarios. In Givisiez, et al. (2020), relevant techniques for different TSO-DSO coordination schemes are reviewed and investigated. Edmunds et al. (2020) have proposed a novel market-based TSO-DSO coordination scheme compatible with existing TSO balancing market operation, where the DSO is given priority in using DERs to manage distribution network constraints. However, it is important to note that there is still significant flexibility for the TSO even during periods of peak demand and maximum export. Results of the case studies conducted as demonstrated on a section of Great Britain distribution network using high DER growth scenario data for the year 2030, show that the proposed approach is able to maintain thermal and voltage limits during periods of peak demand and DER output. In Grøttum et al. (2019), a multiobjective optimization method TSO-DSO coordination with flexibility supplied by DERs is proposed, where the flexibility is obtained by minimizing the overall cost of power system operations as well as the impact of including the cost across the two levels in the coordinated power system. Results indicate that the conflicting interests of the TSO and the DSOs can be considered using the proposed multiobjective optimization method. In Papalexopoulos et al. (2020), a nodalbased electricity market for the distribution network is proposed using both a day ahead market (DAM) and a real-time market (RTM) to manage offers and bids submitted by the DERs. Furthermore, a mixed integer programming (MIP), security constrained unit commitment (SCUC), and a security constrained economic dispatch (SCED) iterate with an asymmetric and unbalanced three-phased distribution power flow (DPF) in order to comply with all constraints in the distribution network. The nodal-based approach produces distribution locational marginal prices (DLMPs) for all phases at each node. Results indicate the validity of the proposed approach for a range of scenarios. In Riaz and Mancarella (2019), the potential of virtual power plants (VPPs) is exploited to coordinate operation at the TSO-DSO boundary interface. Results from a range of case studies highlight the impact of flexible load and network topology on VPP potential.

In particular, information and data exchange via cloud computing platforms is considered a key research area for future smart grids (Radi et al., 2019; Suljanović et al., 2019; Taylor et al., 2019). In this study, the use of DSO-connected resources for balancing purposes in the market environment is proposed. It is also important to note that the proposed method implements the necessary information and data exchange between TSOs and DSOs using a cloud computing platform approach. The proposed approach supports increasing 
volumes and speeds of the necessary information and data exchange. In this study, the evaluation of the proposed balancing approach is performed via a business use case (BUC) that is designed based on the categorization of IEC 62,913-1 ${ }^{1}$ (Gottschalk et al., 2017). Furthermore, two different scenarios are considered to validate the data modeling as well as the information and data exchange mechanisms between the DSO and the TSO at preoperational, operational, and postoperational time scales. In the first case, a novel scenario, where data are exchanged between the TSO, the DSO, and the balancing service provider (BSP), is analyzed. In the second case, a scenario where data are exchanged directly between the TSO and the DSO as the BSP, is studied. In this scenario, it is intended that the TSO can benefit from the DSO demand response mechanisms, such as the conservation voltage reduction (CVR), when providing balancing services. In this study, the focus is on the provision of tertiary balancing services, such as manual frequency restoration reserve (mFRR). In addition, secondary services, such as automatic frequency restoration reserve (aFRR) and frequency containment reserves (FCR), are also considered.

The main objective of this study was to propose and develop a novel use case methodology to support enhanced TSO-DSO information and data exchange for integrating the ancillary services provided by flexibility resources connected to a distribution network that can be efficiently exploited in a balancing market, which is a crucial task toward successfully managing distribution networks with large penetration of DG and DER (Pilo et al., 2017). In particular, a cloud computing approach is investigated in this study as the main platform for exchanging the information and data between the TSOs, DSOs, and other stakeholders such as BSPs, in order to ensure the information and data can be exchanged at the required volumes and speeds. The remainder of the article is organized as follows. In Section Scope and Development of Use Case Methodology, the scope and development of the proposed use case methodology is presented. In section Business Use Case Definition, the proposed BUC is presented and its main characteristics are defined. In Section BUC design, the BUC design is implemented. In Section Business Use Case Analysis, the information and data as exchanged in the BUC are analyzed based on two scenarios. Finally, conclusions and future research are presented in Section Conclusion.

\section{SCOPE AND DEVELOPMENT OF USE CASE METHODOLOGY}

This study reports on research performed in the TDX-ASSIST ${ }^{2}$ project that aims to design and develop novel ICT tools and techniques that facilitate scalable and secure information systems and data exchange between TSOs and DSOs (TDX-ASSIST Project 2017a; TDX-ASSIST Project 2017b; TDX-ASSIST
Project 2017c). Figure 1 presents the TSO-DSO coordination of the energy system market environment in terms of the smart grid architecture model (SGAM) and related IEC standards (Uslar et al., 2019).

In this context, the TSO-DSO coordination and interaction that is addressed in this study is highlighted with the squared area in blue in Figure 1. In particular, the information and data exchange mechanism between TSO and DSO as proposed in this study extends or modifies the existing IEC standards as presented in Figure $\mathbf{1}$ and as based on the use of a cloud computing platform.

In order to support widespread integration of DG and RES by improving TSO-DSO information and data exchange mechanisms, it is essential to understand the quantities and types of information and data that TSOs and DSOs are required to exchange (Silva et al., 2012). In order to determine the necessary information and data to be exchanged as well as to evaluate the feasibility, the proposed novel use case approach is implemented with regard to different real-world scenarios, mapped to the IEC standards framework as shown in Figure 1. Subsequently, a BUC enabling the activation of DSO-connected resources for balancing purposes in the market environment is designed. The proposed BUC is designed based on the categorization of IEC 62,913-1 introduced in (Gottschalk et al., 2017), which is a canonical and well-structured use case methodology that is closely related to SGAM applications. In addition, the proposed BUC is created using enterprise architect (EA) which is a tool of SPARX SYSTEMS ${ }^{3}$. In particular, an extension of EA as developed by EDF called MODSARUS ${ }^{4}$ is used since it allows bringing to EA a model-driven approach to specify unambiguous, interoperable, and vendor-independent SGAM applications. In this way, a well-structured and standardized methodology, widely used in the field (Gottschalk et al., 2017; Hooshyar and Vanfretti. 2017; Mliavaccaig et al., 2017; Natale et al., 2019), based on standardized methods and tools, such as IEC SyC Smart Energy 62559-2 use case methodology, unified modeling language (UML), and EA, is used to validate the proposed data modeling and information exchange mechanisms between DSOs and TSOs in order to exploit DSO-connected resources for balancing purposes.

\section{BUSINESS USE CASE DEFINITION}

Figure 2 presents an overview of the proposed BUC. For implementation purposes, it is assumed that the DSO provides demand response as a balancing capacity in the balancing market and that the TSO, DSO, and BSP have direct physical connections. In addition, it is important to note that the exchange of information and data in operational planning will be highly dependent on the rules of the different balancing markets and that the particular market mechanism proposed 


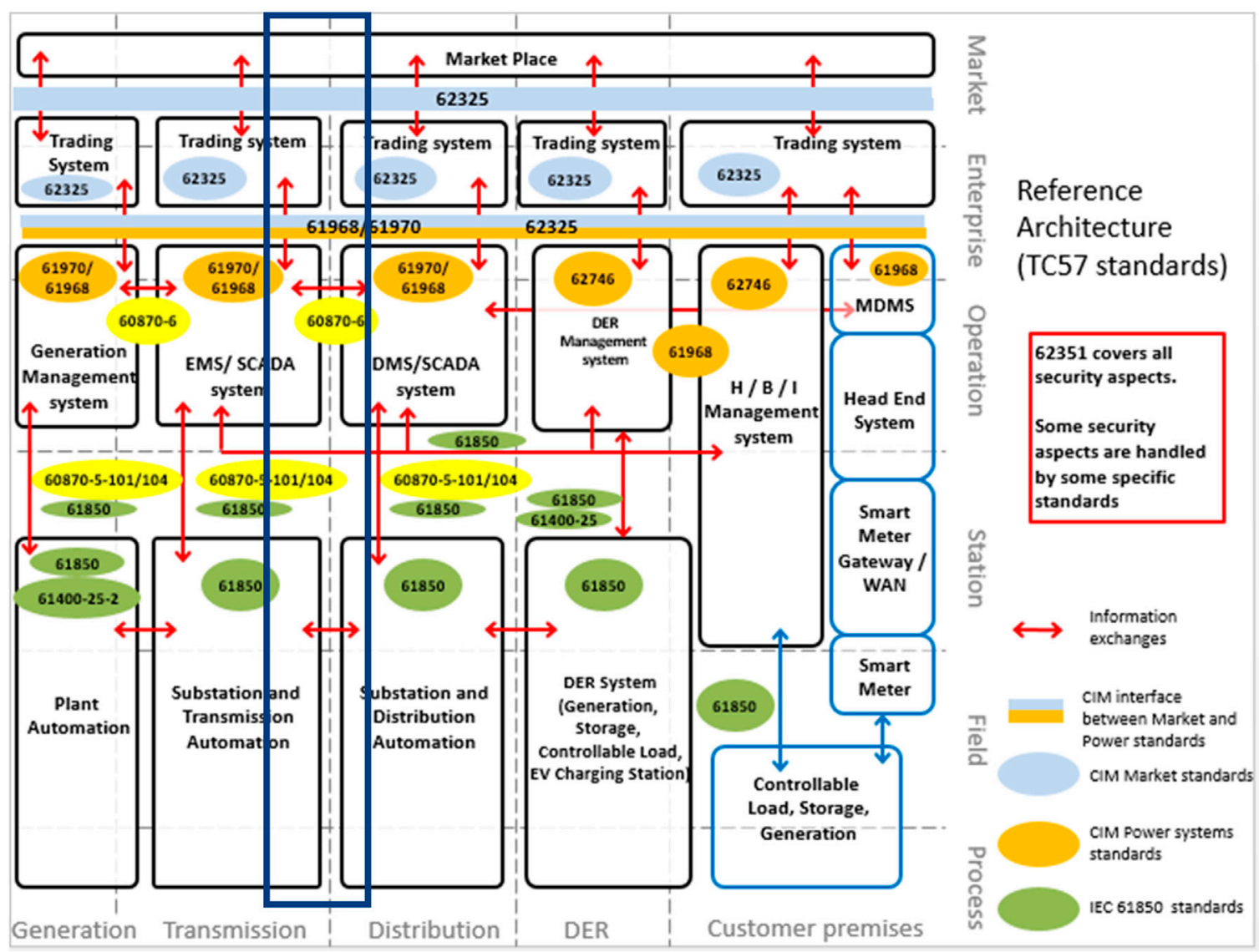

FIGURE 1 | TSO-DSO coordination of the energy system market environment based on SGAM and related IEC standards (Hooshyar and Vanfretti. 2017).

in the BUC can impact on the congestion management (Gerard et al., 2018).

The business actors of the proposed BUC are the, TSO, DSO, and BSP, which relate to the main objectives as follows:

1. Improve overall system security.

2. Prove the capability of the DSO to provide balancing services for the benefit of the TSO using demand response mechanisms.

3. Validate the information exchange between the TSO and the DSO as required for activation of DSO-connected resources for balancing purposes in a market environment.

4. Evaluate the DSO participation within the balancing services market.

Each of the objectives can be associated with a key performance indicator (KPI) that will be measured in order to evaluate the effectives of the proposed use case methodology. In particular, the measured KPIs are as follows:

1. Capability of platform to exchange information and data: This KPI is validated by evaluating the implementation of the platform for information and data. It is associated with objectives 1 and 2 .
2. Quantity of demand response activated: This KPI can be measured in activated power or in number of activated offers. It is associated with objective 3 .

3. Participation of the DSO in the balancing service. This KPI is associated with objective 4 .

\section{BUC DESIGN}

Two different scenarios are considered in the proposed BUC. Figure 3 shows a diagram of the proposed BUC and the two developed scenarios. The first scenario is consistent with existing power systems and market concepts, in which the balancing services are mainly ensured by BSPs in competition with large generators. In this scenario, the BSP provides services directly for the benefit of the TSO even when the resources are connected to the distribution network. In addition, two different situations are considered in this scenario. The first one corresponds to the case where the DSO does not participate in the offering process. The second one, on the contrary, corresponds to the case where the DSO does participate in the offering process. In this way, it is intended to evaluate the impact of the DSO participation in 


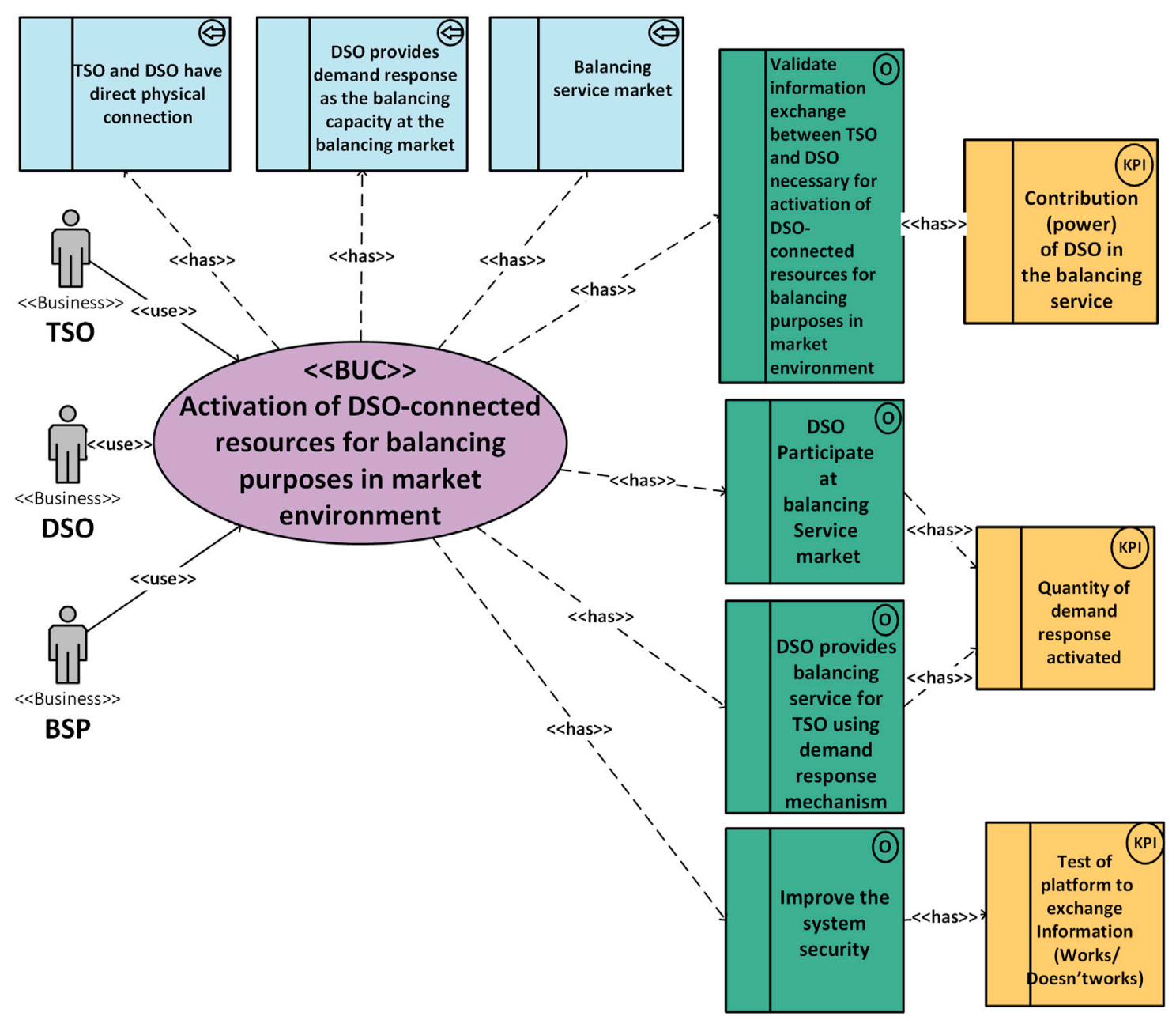

FIGURE 2 | BUC Activation of DSO-connected resources for balancing purposes in a market environment.

the offering process in the whole system, as well as the advantages and limits of such participation.

The second scenario represents a potential prospect, where DERs will also be operated in a competitive framework (Mliavaccaig et al., 2017). In this context, the second scenario does not necessarily reflect the current situation for most power systems, as it consists of the TSO benefiting from the demand response operated by the DSO. In order to study the actual feasibility of this particular proposed scenario, identifying its advantages, barriers, and limits, different solutions, such as local DER operated by multiple BSPs or by a single one, specifically, the DSO, can be tested.

\section{BUC ANALYSIS}

The BUC analysis for the design of each scenario is introduced in this section whereby the steps and procedures for applying each one are elaborated.

\section{Scenario I: BSP Provides Balancing Capacity Using Assets Connected to the Distribution Network}

Within the context of this scenario, which is consistent with the current situation in most power systems, the BSP is responsible for providing balancing capacity using assets that are connected to the distribution network. Here, the DSO will participate in the prequalification process toward technically validating the services. In addition, two different situations are considered in the context of the offering process. In the first one, the DSO does not participate. In the second one, the DSO can participate through validation by the merit order list (MOL) as defined by the TSO and based on its impact at the distribution system level. The different steps in scenario I the prequalification, the offering, the activation of balancing capacity, and the imbalance settlement are described in detail in subsections Pre-qualification, Offering, Activation of Balancing Capacity, and Imbalance Settlement, respectively. 


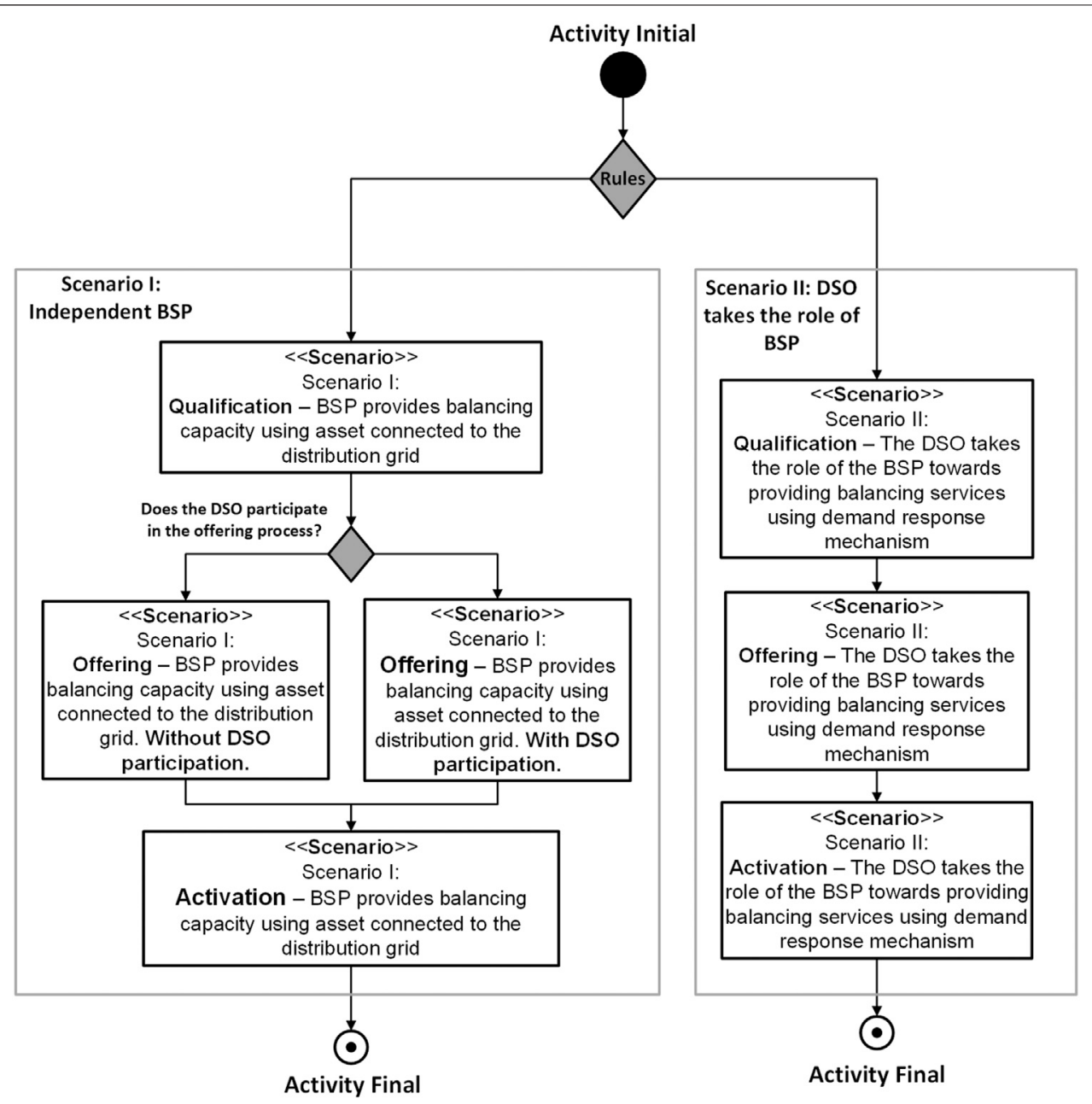

FIGURE 3 | Activity diagram of the proposed BUC.

\section{Prequalification}

In the prequalification process, the TSO collects data from each BSP intending to provide balancing energy or balancing capacity.

The BSP assets are connected to the distribution network, in close cooperation with the DSO, in order to ensure that the party connected to the network is appropriately included in the process. In this context, BSPs are responsible for guaranteeing adequate unit features, measurement, and communication capabilities. In addition, the BSP should also prequalify the distributed flexibility resource (DFR) activation, even if the service is provided by an aggregator managing several individual resources, whereas the DSO should be involved in the prequalification process for the resources connected in the distribution network. Figure 4 shows the qualification diagram corresponding to the first scenario. The different steps involved in this stage are described as follows:

1. Request for prequalification and location of units such as the DFRs: The BSP sends technical data to the TSO for prequalification to guarantee adequate unit features, such as preparation period, ramping period, full activation time, minimum and maximum quantity, deactivation period, and minimum and maximum duration of activation period.

2. Send prequalification data: If the BSP is acting as an aggregator and manages a pool of DFRs then the activation scheme, which is distributed among the individual units, must be prequalified and validated by the DSO.

3. Balancing capacity validation: The DSO validates the balancing capacity in order to prevent congestion in the distribution network. Based on the received data and models, the DSO runs tests to evaluate whether the activation service will have a negative impact on the distribution network leading, for instance, to network congestion or overload of the transformer at the TSO-DSO interface. In the particular scenario proposed in this study, the DSO role in the validation process depends on its participation in the offering process. On one hand, if the DSO does not participate in the offering process, the DSO should validate the complete activation of all balancing capacity to 


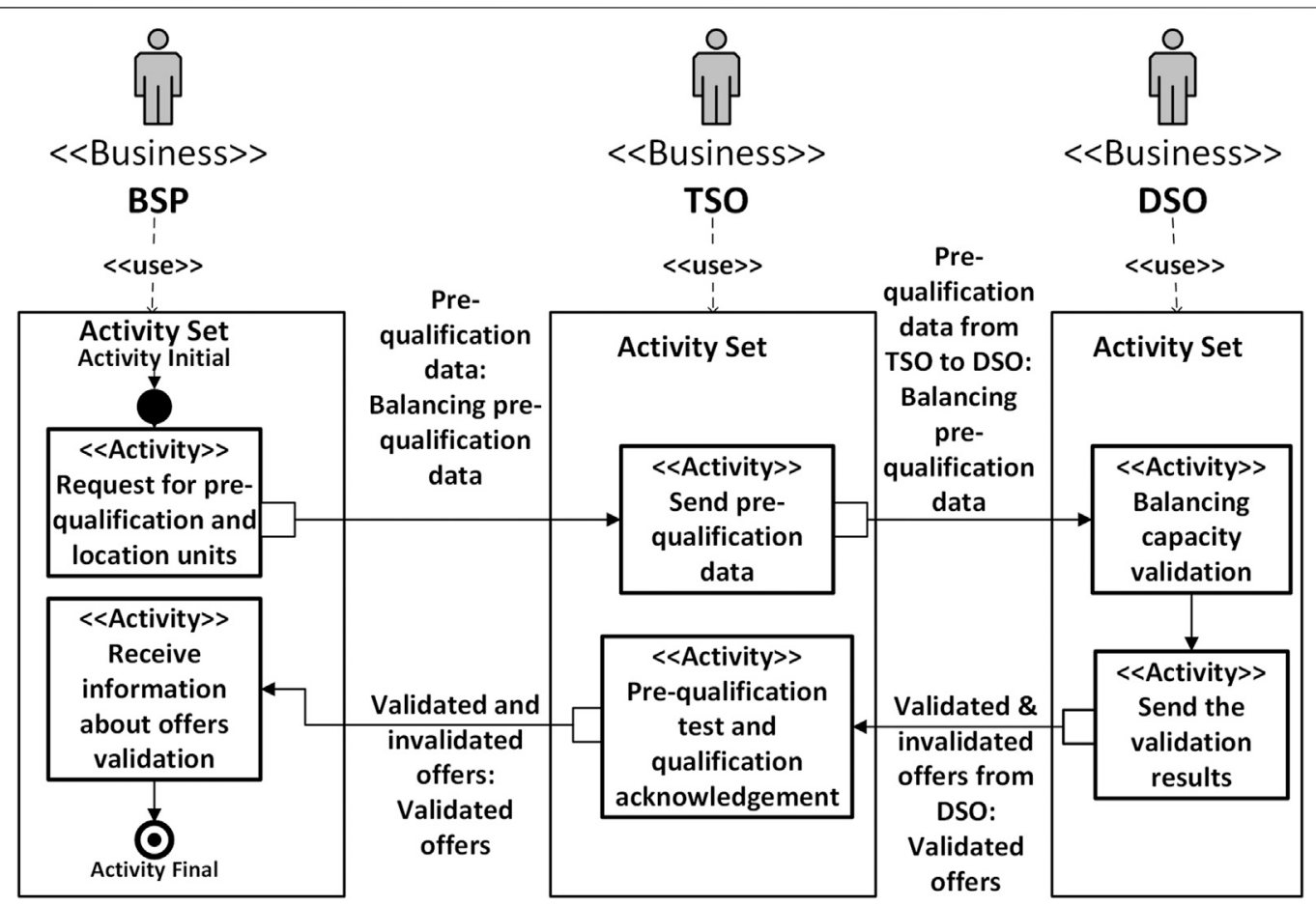

FIGURE 4 | Scenario I-Qualification: The BSP provides balancing capacity using assets connected to the distribution network.

avoid constraints. On the other hand, if the DSO participates in the offering process, the DSO should only validate the impact of separate balancing capacity, without considering the activation of all balancing capacity.

4. Send the validation results: The DSO sends the validation documents confirming that balancing power can be transported through the distribution network. In the case that the tests ran in step 3 have failed, the DSO provides such tests results and sends a negative answer to the TSO for activation of balancing products, however, in some cases the balancing power can still be provided and the DSO can give an upper limit to the BSP.

5. Prequalification test and qualification acknowledgement: The TSO performs prequalification tests and, provided the requirements are fulfilled, sends qualification acknowledgment to BSPs.

6. Receive information about offer validation: The BSP receives the information about the validated offers.

\section{Offering}

In the offering process, the TSO procures both aFRR and mFRR capacity through tendering procedure. Before real-time operation, TSO collects individual offers from BSPs in its control area in order to create the MOL. In this case, two different situations are considered:

1. DSO does not participate in the offering process: In this case, the DSO should prequalify the BSP considering that all BSPs in the same distribution network will be activated.

2. DSO participates in the offering process: In this case, the TSO will prequalify the BSPs based on their individual impact in the distribution network, allowing the DSO to limit the use of BSP services in the offering process.

Figure 5 presents the offering schematic corresponding to the first situation described above where the DSO does not participate in the offering process.

The different steps involved in this case are described as follows:

1. Sending balancing capacity offer: BSPs send balancing capacity offer to TSO.

2. Balancing capacity offer reception: The TSO receives the balancing capacity offers.

3. Gate closure.

4. MOL definition: The TSO creates the MOL based on the received orders.

5. Send offers acceptance confirmation: After gate closure and MOL creation, the TSO sends offer acceptance confirmation to the DSO (which has not participated in the entire offering process), and to the BSP, respectively.

6. Receive offer acceptance confirmation: The BSP and the DSO, respectively, receive the offer acceptance confirmation from the TSO.

Figure 6 presents the offering schematic corresponding to the case where the DSO does participate in the offering process. The different steps involved in this case are as follows: 


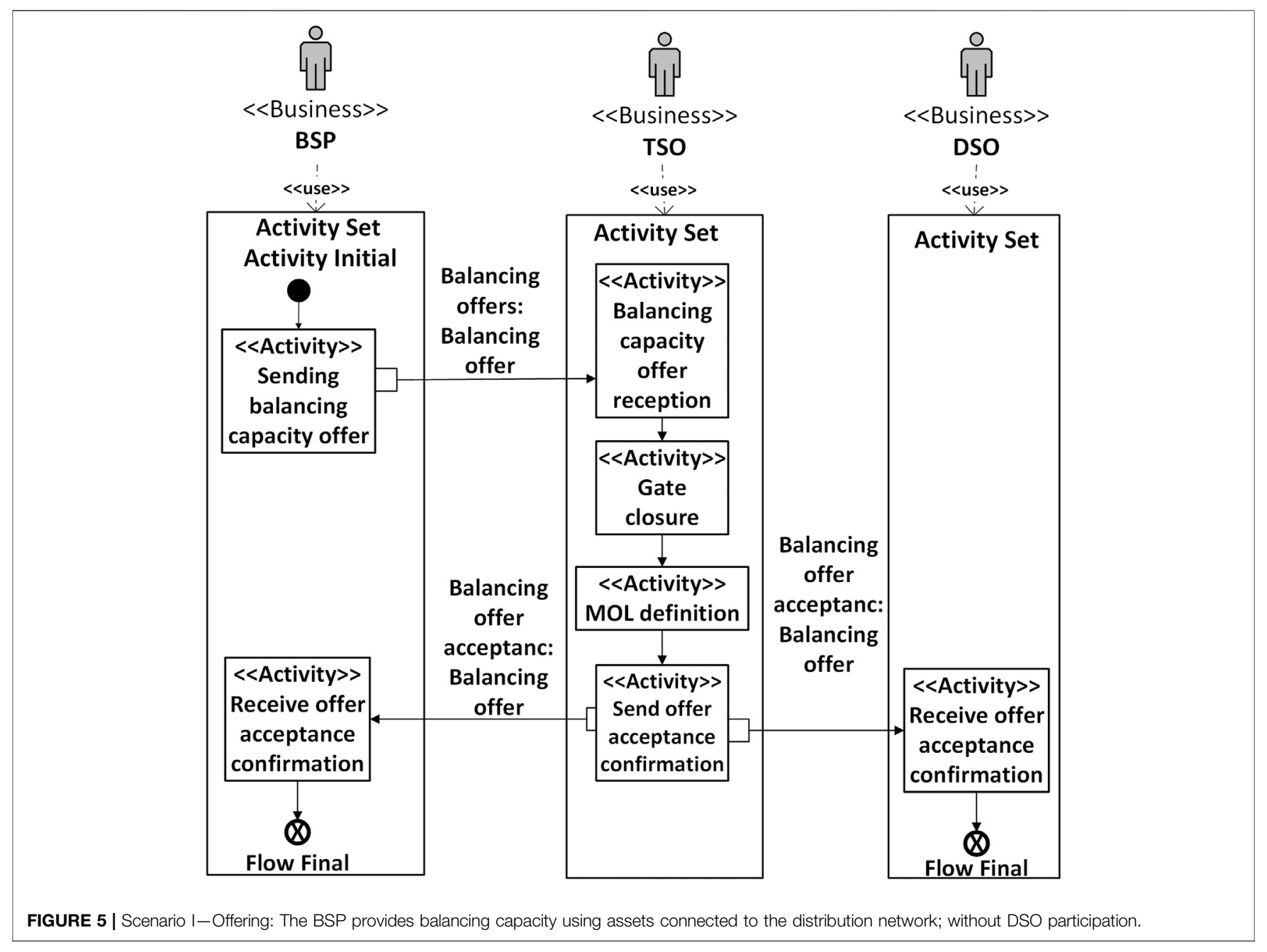

1. Sending balancing capacity offer: The BSP sends balancing capacity offers to the TSO.

2. Balancing capacity offer reception: The TSO receives the balancing capacity offers.

3. Gate closure.

4. MOL definition: The TSO creates the MOL based on the received orders.

5. Technical validation: In this step, the DSO participation in the offering process takes place. The DSO technically validates the MOL of BSPs connected in the distribution network.

6. MOL validation reception: The TSO receives the MOL validation information from the DSO.

7. TSO creates definitive MOL: The TSO creates definitive MOL based on the DSO technical validation.

8. Send offers acceptance confirmation: After MOL validation and definitive creation, the TSO sends offer acceptance confirmation, to the BSP and the DSO, respectively.

9. Receive offer acceptance confirmation: The BSP and the DSO receive the offer acceptance confirmation from the TSO.

\section{Activation of Balancing Capacity}

The activation of the balancing capacity is based on the created MOL. It is important to note that in the case that the DSO participates in the offering process, the MOL is validated by the DSO based on its impact on the distribution network. In the activation process, the BSP sends real-time information to the TSO and archives data for ex post monitoring. Once this information is available, the DSO can limit the activation of offers that could violate distribution network limits, causing unwanted issues, such as congestion. Figure 7 presents the schematic corresponding to the activation process. The different steps involved in this stage are as follows:

1. Activation signal dispatch: The TSO sends activation signals based on the definitive MOL computed in the previous offering process.

2. Activation of offers: The BSP activates the offers.

3. Send real-time information: The BSP sends real-time information about pool measurements, activated power, and baseline measurement to the TSO. 


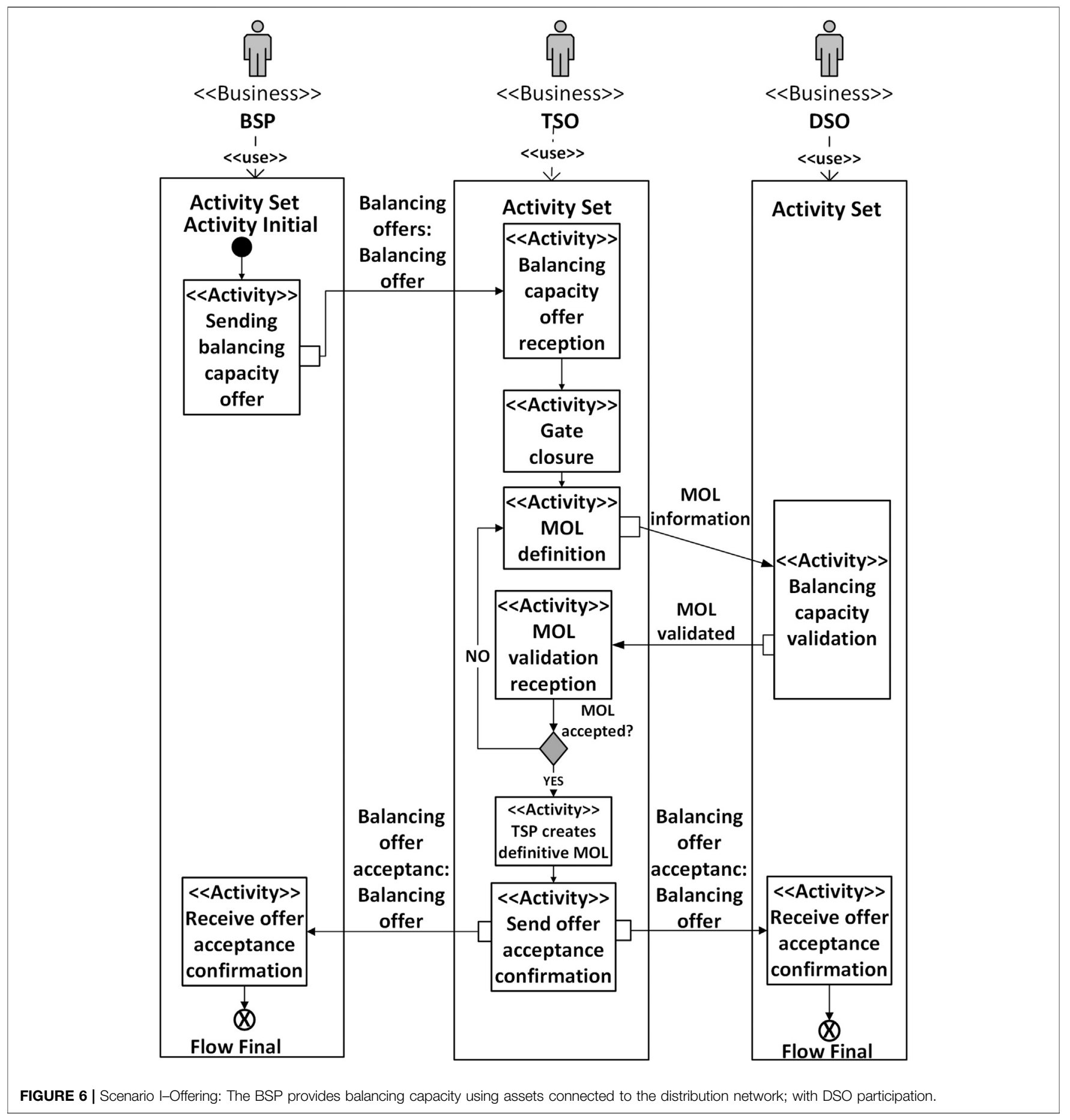

4. Real-time information reception: The TSO receives the real-time information.

5. Control of offers activation or modification: The TSO controls the correct activation and/or modification of the offers.

6. Monitor measurements: The DSO monitors the measurements toward making sure that no constraints appear in the network.
7. Send limit activation and power measurements to TSO: If activation has negative impact on the distribution grid, DSO limits the activation by sending a termination signal to the TSO. Then, the TSO terminates the activation and activates another balancing capacity.

8. Send limit activation to the BSP The limit activation generated in step 7 is sent to the BSP. 


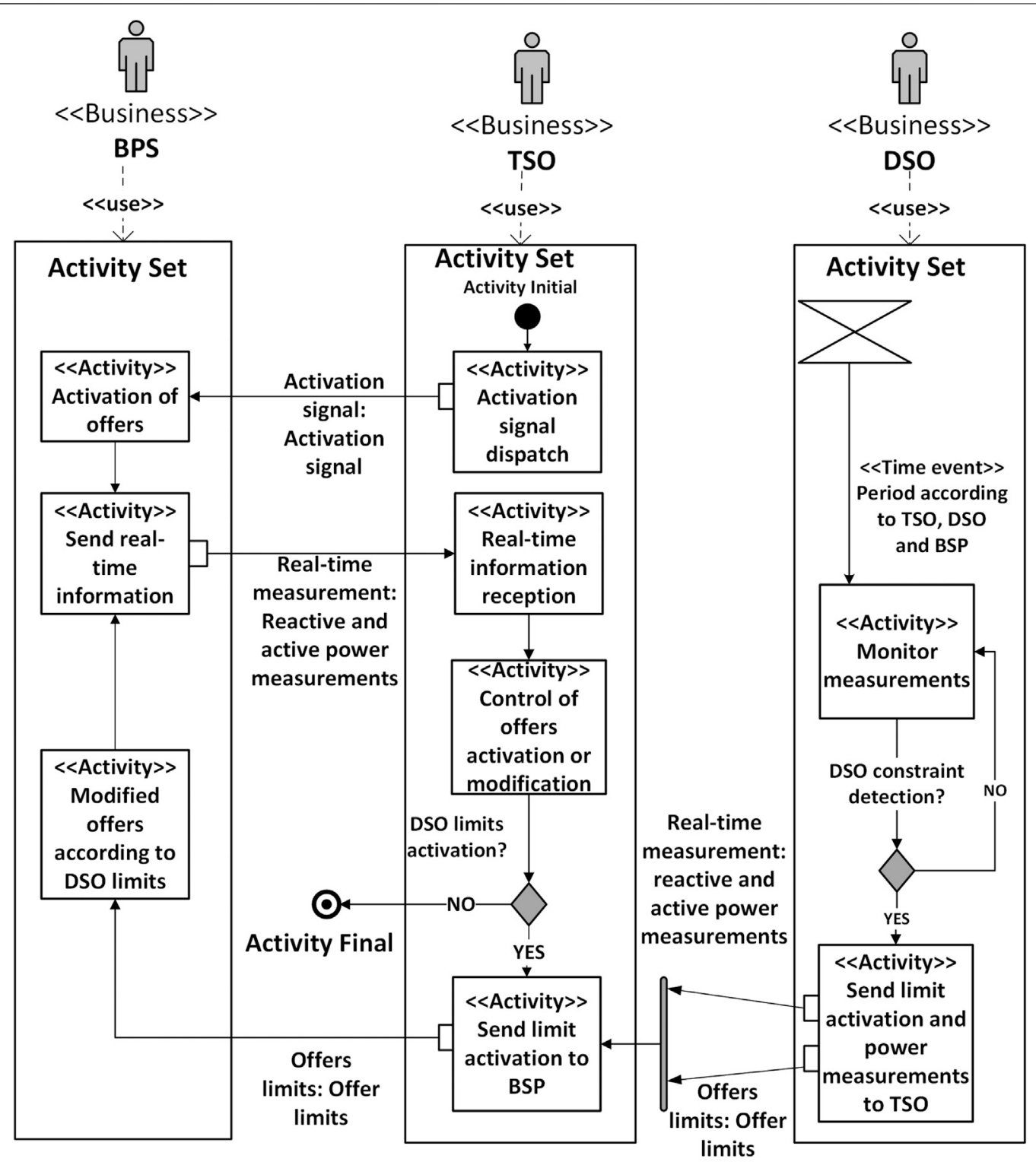

FIGURE 7 | Scenario I-Activation: The BSP provides balancing capacity using assets connected to the distribution network.

9. Modify offers according to DSO limits The BSP modifies the offers according to the DSO limits.

\section{Imbalance Settlement}

In this scenario, the imbalance settlement between the TSO and the BSPs is implemented using the pay-as-bid principle (ENTSO-E. 2017). The delivered energy is settled in accordance with the metered response for aFRR and requested response for mFRR.

\section{Exchanged Information}

Table 1 shows the information and data this exchanged as a result of the application of the proposed mechanism based on the use of a cloud computing platform within the framework of the scenario analyzed in this section.

\section{Scenario II: The TSO Uses the DSO Demand Response Mechanism for Balancing Purposes}

Although most of the balancing services are currently provided by BSPs in competition with large generators, it is expected that, in a near future, DER will also be operated in a competitive framework. This scenario involves the TSO using the demand response operated by the DSO and with the DSO playing the role of the BSP. In this way, it is intended that this scenario, which has been especially designed for evaluating purposes and does not necessarily reflect the current ENTSO-E $\mathrm{E}^{5}$ position, can be viewed as a transitional solution,

${ }^{5}$ https://www.entsoe.eu/ 
TABLE 1 | Scenario I: Exchanged information.

\begin{tabular}{|c|c|c|c|c|}
\hline INFO ID & Type & Description & BUC stage & From-to \\
\hline \multirow[t]{2}{*}{ INFO 1} & Balancing prequalification & Information with the qualified BSP. If the BSP is an & Prequalification Step 1 & BSP-TSO \\
\hline & data & $\begin{array}{l}\text { aggregator, the qualification should be done for all } \\
\text { the aggregated resources }\end{array}$ & Prequalification Step 2 & TSO-BSP \\
\hline \multirow[t]{2}{*}{ INFO 2} & Validated offers & Depending on the market rules, the DSO can & Prequalification Step 4 & DSO-TSO \\
\hline & & exclude the offers or send the limits in the use of the offers & Prequalification Step 5 & TSO-BSP \\
\hline \multirow[t]{6}{*}{ INFO 3} & Balancing offer & - Power (regulation up) & Offering (without DSO participation) & \\
\hline & & - Time & Step 1 & BSP-TSO \\
\hline & & & Steps 5, 6 & $\begin{array}{l}\text { TSO- } \\
\text { DSO, BSP }\end{array}$ \\
\hline & & & Offering (with DSO participation) & \\
\hline & & & Step 1 & BSP-TSO \\
\hline & & & Steps 8,9 & $\begin{array}{l}\text { TSO-DSO, } \\
\text { BSP }\end{array}$ \\
\hline INFO 4 & MOL information & $\begin{array}{l}\text { The MOL is created for each period ( } 1 \mathrm{~h}, 30 \mathrm{~min} \text {, or } 15 \mathrm{~min} \text { ). } \\
\text { The MOL should include the active power and the activation } \\
\text { point }\end{array}$ & Offering (with DSO participation) Step 4 & TSO-DSO \\
\hline INFO 5 & MOL validated & $\begin{array}{l}\text { Validated offers cleared in the market. The information can be } \\
\text { the offer ID }\end{array}$ & Offering (with DSO participation) Step 5 & DSO-TSO \\
\hline INFO 6 & Activation signal & Signal to activate the offer & Activation Step 1 & TSO-BSP \\
\hline \multirow[t]{2}{*}{ INFO 7} & Reactive and active power & The reactive power $(Q)$ is expressed in MVAr, whereas the & Activation Step 3 & BSP-TSO \\
\hline & measurements & active power $(\mathrm{P})$ is expressed in $\mathrm{MW}$. & Activation Step 7 & DSO-TSO \\
\hline \multirow[t]{2}{*}{ INFO 8} & Offers limits & Limits to be applied to the balancing offers & Activation Step 7 & DSO-TSO \\
\hline & & & Activation Step 8 & TSO-BSP \\
\hline
\end{tabular}

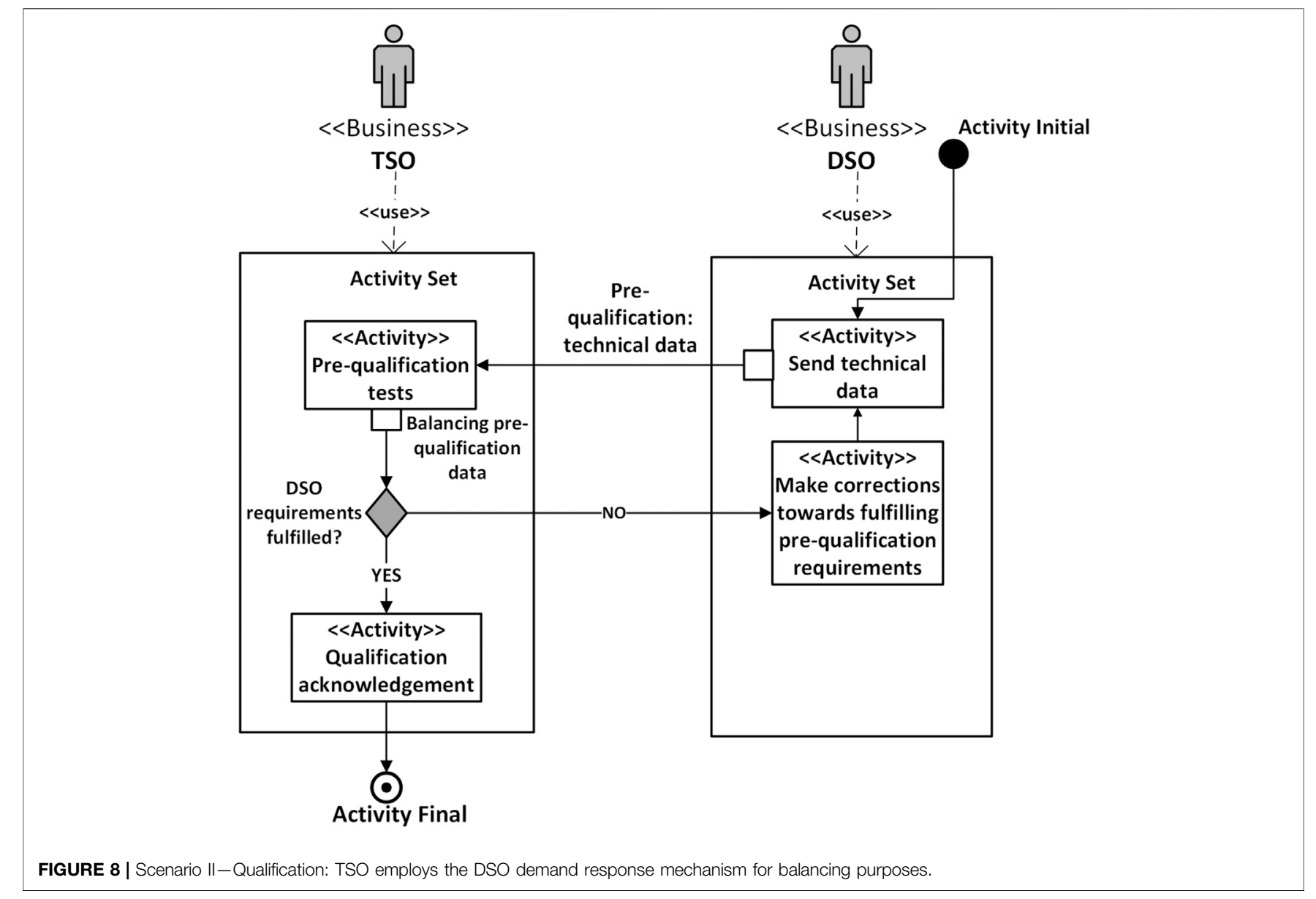




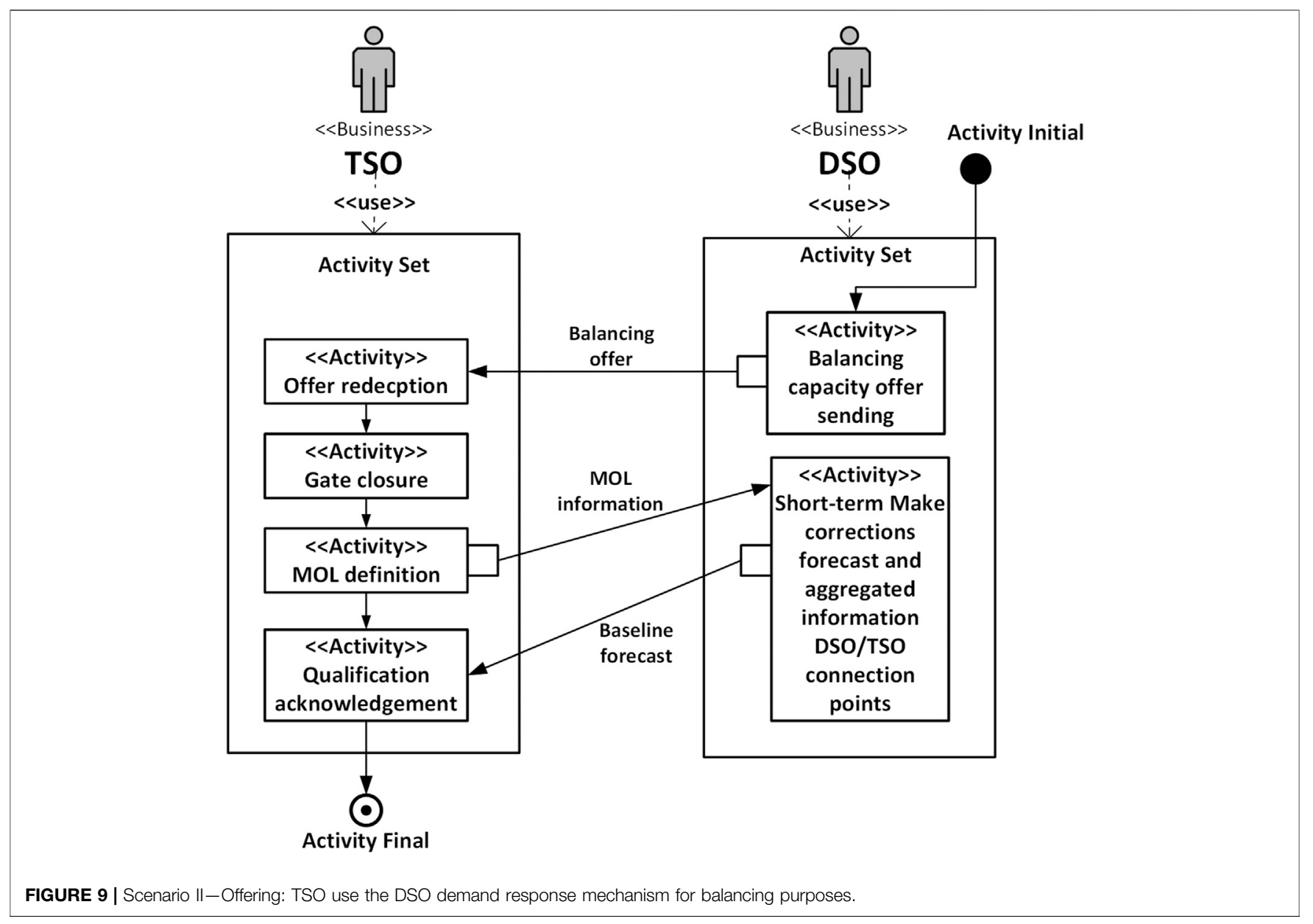

mitigating the fact that the single TSO-DSO services market is not yet a reality. The different steps required in scenario II the prequalification, the offering, the activation of balancing capacity, and the imbalance settlement are described in Subsections Prequalification, Offering, Activation of Balancing Capacity, and Imbalance Settlement, respectively.

\section{Prequalification}

In the prequalification process, the TSO carries out the tests, prior to real-time operation, in order to examine the DSO technical capability for $\mathrm{mFRR} / \mathrm{aFRR}$ provision. Figure 8 presents the prequalification schematic corresponding to this scenario.

The different steps involved in this stage are described as follows:

1. Send technical data: The DSO (playing the traditional role of the BSP) sends technical data to the TSO for prequalification. In this case, where the presence of DSR is taken into account, the DSO should guarantee adequate DSR features.

2. Prequalification tests: The TSO performs prequalification tests. Then, if the DSO prequalification requirements are fulfilled, the qualification acknowledgment is sent to the DSO.
3. Make corrections to fulfill prequalification requirements: If the results of the performed tests in Step 2 do not fulfill the DSO prequalification requirements, the DSO makes corrections toward fulfilling them.

4. Qualification acknowledgment

\section{Offering}

In the offering process, the TSO procures balancing capacity through tendering procedures. Before real-time operation, the TSO collects individual offers from the DSO in its control area in order to create the MOL. Then, during the baseline forecasting, the DSO provides balancing capacity using DSR mechanisms, such as the CVR, as mFRR balancing services. In particular, the DSO provides short-term (hourly scale) consumption forecast to the TSO in advanced with respect to the provided balancing service. The consumption forecast may be either calculated by the available flexibility at a given consumer connection point or at the baseline forecast. In addition, as part of the same process, the DSO must aggregate, whenever needed, the corresponding information from all TSO-DSO connection points or balancing zones. Finally, the DSO provides this information as well as the information about possible limitations due to TSO-DSO network constraints, such as overload of a transformer at TSO-DSO interface, to the TSO. 


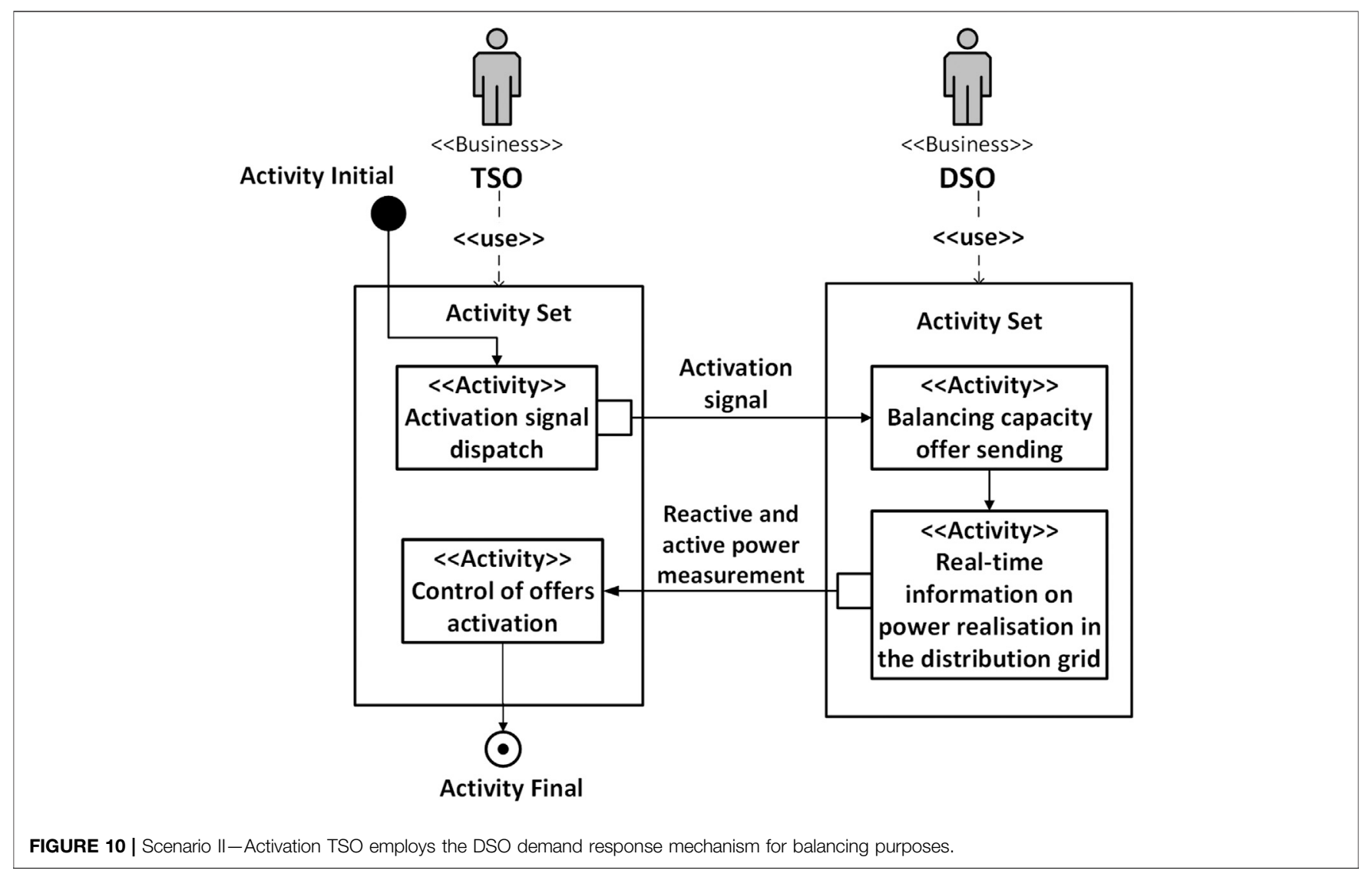

Figure 9 presents the offering schematic corresponding to this scenario. The different steps involved in this offering process are described as follows:

1. Balancing capacity offer sending: The DSO (playing the role of the BSP) sends the balancing capacity offers to the TSO.

2. Offer reception: The TSO receives the balancing capacity offers.

3. Gate closure.

4. MOL definition: The TSO creates the MOL based on the received orders.

5. Short-term consumption forecast and aggregated information from DSO-TSO connection points: The DSO sends short-term consumption forecast to the TSO in advance (with respect to the balancing capacity offer). In addition, the DSO sends aggregated information from all TSO-DSO connection points.

6. Receive consumption forecast and balancing zones: The TSO receives the information about the consumption forecast and balancing zones.

\section{Activation of Balancing Capacity}

The activation of the balancing capacity is based on the created MOL during the offering process. In the activation process, the real-time power consumption is measured and the DSO sends the real-time information about power realization to the TSO. Based on the received information, the TSO monitors the quality of the service parameters and takes adequate actions if these parameters are violated. In the case of the aFRR, real-time information and data exchange is required. In particular, information and data concerning control signal, baseline, and realization is exchanged in real time utilizing the published/subscribed peer-to-peer model (TDX-ASSIST Project. 2017a). In the case of the mFRR, real-time exchange is not necessarily required. The case involves information and data exchange that can occur after service delivery, that is, ex post analysis. It is also important to note that different information and data exchange platforms are available to archive the data and provide it for ex post analysis, such as the ENTSO-E communication and connectivity service platform(ECCo SP $)^{6}$.

Figure 10 presents the schematic corresponding to the activation process. The different steps involved in this stage are as follows:

1. Activation signal dispatch: The TSO sends activation signals based on the definitive MOL computed in the previous offering process.

${ }^{6} \mathrm{https} / / /$ www.entsoe.eu/data/ecp/ 
TABLE 2 | Scenario II: Exchanged information.

\begin{tabular}{|c|c|c|c|c|}
\hline INFO ID & Type & Description & BUC stage & From-to \\
\hline INFO 9 & Prequalification technical data & $\begin{array}{l}\text { DSO sends technical data necessary for prequalification of balancing service } \\
\text { product based on distributed system management (DSM) }\end{array}$ & $\begin{array}{l}\text { Prequalification } \\
\text { Step } 1\end{array}$ & DSO-TSO \\
\hline INFO 1 & Balancing prequalification data & As described in Table 1 & $\begin{array}{l}\text { Prequalification } \\
\text { Step } 1\end{array}$ & TSO-DSO \\
\hline INFO 3 & Balancing offer & As described in Table 1 & Offering Step 1 & DSO-TSO \\
\hline INFO 4 & MOL information & As described in Table 1 & Offering Step 4 & TSO-DSO \\
\hline INFO 10 & Baseline forecast & Forecast of the load profile (active power) & Offering Step 5 & DSO-TSO \\
\hline INFO 6 & Activation signal & As described in Table 1 & Activation Step 1 & TSO-DSO \\
\hline INFO 7 & $\begin{array}{l}\text { Active and reactive power } \\
\text { measurements }\end{array}$ & As described in Table 1 & Activation Step 3 & DSO-TSO \\
\hline
\end{tabular}

2. Activation of flexibilities: The TSO activates the flexibilities.

3. Real-time information on power realization in the distribution grid: The DSO sends real-time information on reactive and active power measurements.

4. Control of offer activation.

\section{Imbalance Settlement}

After the activation, the TSO performs the imbalance settlement and financially compensates the procured power for the balancing service.

\section{Exchanged Information and Data}

As a result of the application of the proposed use case methodology within the framework of the scenario analyzed in this section, the necessary information and data as required to exploit the DSO-connected resources for balancing purposes have been demonstrated between the TSO and the DSO. Table 2 presents the exchanged information and data.

\section{CONCLUSION}

Traditionally, balancing services have been mainly provided at the transmission network level and arranged by TSOs. However, the ongoing widespread integration of RES into distribution networks has created a range of overall system balancing issues and challenges. Therefore, it becomes important to evaluate to what extent ancillary services provided by flexibility resources connected to the distribution network can efficiently be exploited in the balancing market. In this study, a novel use case methodology has been developed to formally define overall system balancing approaches based on exploiting the DSO-connected resources for overall system balancing purposes in a market environment as proposed and evaluated within the real-world scenario via a business use case (BUC) design based on the categorization of IEC 62,913-1.

The proposed BUC formally defined the necessary information and data that have to be exchanged between the
TSO and the DSO in order to exploit the DSO-connected resources for overall system balancing purposes. In addition, it also demonstrated how such real-time information and data are actually exchanged using a cloud computing platform that enables the TSO to benefit from the DSO demand response mechanisms, for providing balancing services, such as mFRR and aFRR.

Designing and analyzing the BUC has also formally defined the required interfaces, information instances, and sequence diagrams that are necessary for the deployment of such a BUC. It is important to note that the proposed use case methodology does not explicitly state how information is modeled or which protocols should be adopted. However, the methodology that was developed in the TDX-ASSIST project has demonstrated novel approaches to information modeling such as common information model (CIM) Radi et al. (2019) as well as novel platforms for information and data exchange such as ENTSO-E ECCo SP, transparency platform (TP), and different cloud computing services (Suljanović et al., 2019).

\section{DATA AVAILABILITY STATEMENT}

The raw data supporting the conclusions of this article will be made available by the authors, without undue reservation.

\section{AUTHOR CONTRIBUTIONS}

All authors listed have made a substantial, direct, and intellectual contribution to the work and approved it for publication.

\section{FUNDING}

The research as presented in this paper is based on the TDXASSIST project that has received funding from the European Union's Horizon 2020 research and innovation program under grant agreement No.774500. 


\section{REFERENCES}

Edmunds, C., Galloway, S., Elders, I., Bush, W., and Telford, R. (2020). Design of a DSOTSO Balancing Market Coordination Scheme for Decentralised Energy IET Generation Transm. Distribution, 14, 707- 718. doi:10.1049/iet-gtd.2019.0865

Entso. (2017). All TSOs' Proposal on Methodologies for Pricing Balancing Energy and Cross-Zonal Capacity Used for the Exchange of Balancing Energy or Operating the Imbalance Netting ProcessPursuant to Article 30(1) and Article 30(3) of Commission Regulation (EU) 2017/", Brussels, Belgium: ENTSO-E.

Gerard, H., Rivero Puente, E. I., and Six, D. (2018). Coordination between Transmission and Distribution System Operators in the Electricity Sector: A Conceptual Framework. Utilities Policy 50, 40-48. doi:10.1016/j.jup.2017.09.011

Givisiez, A. G., Petrou, K., and Ochoa, L. F. (2020). "A Review on TSO-DSO Coordination Models and Solution Techniques." Electric Power Syst. Res. 189: 106659. doi:10.1016/j.epsr.2020.106659

Gottschalk, M., Uslar, M., and Delfs, C. (2017). The Use Case and Smart Grid Architecture Model Approach: The IEC 62559-2 Use Case Template and the SGAM Applied in Various Domains. Brussels, Belgium: Springer.

Grøttum, H. H, Bjerland, S. F., del Granado, P. C., and Egging, R. (2019). Modelling TSO-DSO Coordination: The Value of Distributed Flexible Resources to the Power System. In 2019 16th International Conference on the European Energy Market (EEM). 1-6.

Hooshyar, H., and Vanfretti, L. (2017). A SGAM-Based Architecture for Synchrophasor Applications Facilitating TSO/DSO Interactions. In 2017 IEEE Power \& Energy Society Innovative Smart Grid Technologies Conference (ISGT). 1-5.

Lembo, G. D., Agnetta, V., Fiorenza, G., and Giannuzzi, G. (2009). Integration of DSO Control Systems and TSO Automatic Load Shedding System to Improve the Security of the National Grid. "IET Conf. Publications. 550, 8-11. doi:10. 1049/cp.2009.0703

Li, Y., Zhang, H., Liang, X., and Huang, B. (2019). Event-Triggered-Based Distributed Cooperative Energy Management for Multienergy Systems. IEEE Trans. Ind. Inform. 15 (4), 2008-2022. doi:10.1109/TII.2018.2862436

Mliavaccaig, G., Rossi, M., Six, D., Džamarija, M., Horsmanheimo, S., Madina, C., et al. (2017). SmartNet: H2020 Project Analysing TSO--DSO Interaction to Enable Ancillary Services Provision from Distribution Networks. CIRED-Open Access Proc. J. 2017 (1), 1998-2002.

Natale, N., Pilo, F., Pisano, G., and Soma, G. G (2019). "Scheduled Profile at TSO/DSO Interface for Reducing Balancing Costs." in 2019 1st International Conference On Energy Transition In the Mediterranean Area. Synergy Med 1-6.

Papalexopoulos, A., Rod, F., and Alexios, B. (2020). "On the Development of Organized Nodal Local Energy Markets and a Framework for the TSO-DSO Coordination." Electric Power Systems Research 189: 106810

Pilo, F., Mauri, G., Bak-Jensen, B., Kämpf, E., Taylor, J., and Silvestro, F. (2017). Control and Automation Functions at the TSO and DSO Interface--Impact on Network Planning. CIRED-Open Access Proc. J. 2017 (1), 2188-2191.

Radi, M., Taylor, G., Uslar, M., Köhlke, J., and Suljanovic, N. (2019). "Bidirectional Power and Data Flow via Enhanced Portal Based TSO-DSO Coordination. "2019 54th International Universities Power Engineering Conference (UPEC), Bucharest, Romania, 3-6 Sept. 2019. doi:10.1109/UPEC.2019.8893602

Riaz, S., and Mancarella, P. (2019). "On Feasibility and Flexibility Operating Regions of Virtual Power Plants and TSO/DSO Interfaces". In 2019 IEEE Milan PowerTech, 1-6. doi:10.1109/PTC.2019.8810638

Rossi, M., Migliavacca, G., Viganò, G., Siface, D., Madina, C., Gomez, I., et al. (2020). "TSO-DSO Coordination to Acquire Services from Distribution Grids: Simulations, Cost-Benefit Analysis and Regulatory Conclusions from the SmartNet Project." Electric Power Syst. Res. 189, 106700. doi:10.1016/j.epsr.2020.106700

Ruan, H., Gao, H., Liu, Y., Wang, L., and Liu, J. (2020). Distributed Voltage Control in Active Distribution Network Considering Renewable Energy: A Novel Network Partitioning Method. IEEE Trans. Power Syst. 35 (6), 4220-4231. doi:10.1109/TPWRS.2020.3000984
Saint-Pierre, A., and Mancarella, P. (2017). Active Distribution System Management: A Dual-Horizon Scheduling Framework for DSO/TSO Interface under Uncertainty. IEEE Trans. Smart Grid 8 (5), 2186-2197. doi:10.1109/TSG.2016.2518084

Sbordone, D., Maria Carlini, E., Di Pietra, B., and Devetsikiotis, M. (2015). The Future Interaction between Virtual Aggregator-TSO-DSO to Increase DG Penetration. In 2015 International Conference on Smart Grid and Clean Energy Technologies. (Offenburg, Germany: ICSGCE). 201-205.

Silva, J., Sumaili, J., Bessa, R. J., Seca, L., Matos, M. A., Miranda, V., et al. (2018). Estimating the Active and Reactive Power Flexibility Area at the TSO-DSO Interface. IEEE Trans. Power Syst. 33 (5), 4741-4750. doi:10.1109/TPWRS. 2018.2805765

Silva, N., Maia Bernardo, A., Pestana, R., Mota Pinto, C., Carrapatoso, A., and Dias, S. (2012). "Interaction between DSO and TSO to Increase DG Penetration - the Portuguese Example-4IET. In CIRED 2012 Workshop: Integration of Renewables into the Distribution Grid, 29-30 May 2012, Lisbon, Portugal, 1. doi:10.1049/cp.2012.0885

Suljanović, N., Souvent, A., Taylor, G., Radi, M., Cantenot, J., Lambert, E., et al. (2019). Design of Interoperable Communication Architecture for TSO-DSO Data Exchange. IEEE Milan PowerTech. 1-6.

Taylor, G., Radi, M., Lambert, E., Frank, M., and Uslar, M. (2019). Design and Development of Enhanced Data Exchange to Enable Future TSO-DSO Interoperability. In CIGRE SC D2 Symposium. Helsinki: Finland. Availableat: http://bura.brunel.ac.uk/handle/2438/18595.

TDX-ASSIST Project (2017a). "Deliverable D1.1, State of the Art - TSO-DSO Interoperability." Horizon 2020. Brussels, Belgium: the EU Framework Programme for Research \& Innovation.

TDX-ASSIST Project (2017b). "Deliverable D2.1, State of Art Report - Market Participant Interoperability." Horizon 2020. Brussels, Belgium: the EU Framework Programme for Research \& Innovation.

TDX-ASSIST Project (2017c). "Deliverable D3.1 Survey Report - Evolving Data Access Needs." Horizon 2020. Brussels, Belgium: the EU Framework Programme for Research \& Innovation.

Uslar, M., Rohjans, S., Neureiter, C., Velasquez, J., Steinbrink, C., Efthymiou, V., et al. (2019). Applying the Smart Grid Architecture Model for Designing and Validating System-Of-Systems in the Power and Energy Domain: A European Perspective. Energies 12 (2), 258.

van der Veen, R. A. C., and Hakvoort, R. A. (2016). The Electricity Balancing Market: Exploring the Design Challenge. Utilities Policy 43, 186-194. doi:10. 1016/j.jup.2016.10.008

Vicente-Pastor, A, Nieto-Martin, J., Bunn, D. W., and Laur, A. (2019). Evaluation of Flexibility Markets for Retailer-DSO-TSO Coordination. IEEE Transactions on Power Systems. 34, 2003-12.

Yushuai, Li., Gao, W., Gao, W., Zhang, H., and Zhou, J. (2020). A Distributed Double-Newton Descent Algorithm for Cooperative Energy Management of Multiple Energy Bodies in Energy Internet. IEEE Trans. Ind. Inform. 1. doi:10. 1109/TII.2020.3029974

Conflict of Interest: Authors JC and EL were employed by company EDF.

The remaining authors declare that the research was conducted in the absence of any commercial or financial relationships that could be construed as a potential conflict of interest.

Copyright $(2021$ Radi, Taylor, Cantenot, Lambert and Suljanovic. This is an openaccess article distributed under the terms of the Creative Commons Attribution License (CC BY). The use, distribution or reproduction in other forums is permitted, provided the original author(s) and the copyright owner(s) are credited and that the original publication in this journal is cited, in accordance with accepted academic practice. No use, distribution or reproduction is permitted which does not comply with these terms. 